\title{
HeALTH OUTCOMES METRICS AND THE ROLE OF FINANCIAL DERIVATIVE INSTRUMENTS IN THE HEALTH CARE INDUSTRY
}

\author{
EFTHIMIOS PARASIDIS ${ }^{*}$
}

INTRODUCTION 447

I. HEALTH OUTCOMES METRICS 450

II. Health Outcomes-Based Financial DeRIVATIVE INSTRUMENTS

III. CONCLUSION 465

\section{INTRODUCTION}

Despite a culture of innovation, the U.S. health care system has been markedly deficient in its implementation of information technology (IT). ${ }^{1}$ Although recent initiatives have endeavored to remedy this shortcoming, ${ }^{2}$ fragmentation, high costs, information asymmetries, and

* Assistant Professor of Law and Public Health; Moritz College of Law, College of Public Health; The Ohio State University. I presented this work at a symposium titled Imagining the Next Quarter Century of Health Care Law, which was held at the McKinney School of Law at Indiana University, and am grateful for discussions with conference panelists and attendees. I thank Miriam Cherry, Caleb DesRosiers, Gerasimos Petratos, and Javaid Zafar for insightful comments on drafts of this work. A special thanks to the members of the Indiana Health Law Review for their editorial assistance and for organizing a wonderful symposium.

1 See Gary J. Young, Multistakeholder Regional Collaboratives Have Been Key Drivers of Public Reporting, But Now Face Challenges, 31 HEALTH AFFAIRS 578, 582 (March 2012); David Blumenthal \& Marilyn Tavenner, The "Meaningful Use" Regulation for Electronic Health Records, 363 NEw ENG. J. MED. 501, 501 (2010); Carolyn M. Clancy et al., Investing in Health Information Infrastructure: Can It Help Achieve Health Reform?, 28 HEALTH AFF. 478, 478-479 (2009); Ashish K. Jha et al., Use of Electronic Health Records in U.S. Hospitals, 360 NEW ENG. J. MED. 1628 (2009).

2 See Efthimios Parasidis, Patients Over Politics: Addressing Legislative Failure in the Regulation of Medical Products, 2011 WISC. L. REV. 929, 962-71 (discussing public and private initiatives that support health IT). 
evolving regulatory guidance have delayed meaningful adoption of health IT. ${ }^{3}$ At the same time, health IT has been heralded as a panacea that will help stakeholders attain the aspirational goals of reducing health care costs and improving health outcomes. ${ }^{4}$ While the extent to which existing platforms achieve these goals is debatable, there is little doubt that health IT will play an indispensible role for stakeholders throughout the health care industry.

In line with the symposium theme of envisioning the next quarter century of health care law, this Essay explores emerging issues in health IT with a focus on health outcomes metrics and the role of financial derivative instruments in the health care industry. I begin by examining how aggregated patient data can be utilized to create outcomes-based measures such as health outcomes indices (HOIs). HOIs integrate multiple sources of realworld patient data to create metrics that timely and accurately measure the burden of disease, track health status, or evaluate health system performance.

By accurately capturing and measuring patient outcomes over time, HOIs endeavor to provide stakeholders with a valuable tool with which to measure, assess, and predict health outcomes at the population level. Independent validation of HOIs as accurate barometers of patient outcomes will permit use of the metrics for a variety of purposes related to health economics, public health policy, and health care management. One promising avenue relates to $\mathrm{HOI}$-based financial derivative

3 See Young, supra note 1, at 582-83; Michael C. Christensen \& Dahlia Remler, Information and Communications Technology in U.S. Health Care: Why is Adoption So Slow and Is Slower Better?, $34 \mathrm{~J}$. HEAlTH POLITICS, POLICY \& L. 1011, 1014-15 (2009); JAMES W. Henderson, Health ECONOMICS AND Policy 81-89 (2009); Steven H. Woolf et al., Promoting Informed Choice: Transforming Health Care to Dispense Knowledge for Decision Making, 143 ANN. INTERN. MED. 293, 293 (2005), available at https://www.ilr.cornell.edu/healthcare/articles/ upload/Promoting-Informed-Choice-Woolf.pdf.

4 See generally David W. Bates, The Effects of Health Information Technology on Inpatient Care, 169 ARCHIVES INTERNAL MED. 105 (2009); Julia Adler-Milstein et al., U.S. Regional Health Information Organizations: Progress and Challenges, 28 HEALTH AFF. 483 (2009); Jha et al., supra note 1. 
instruments. HOI-based derivatives aim to provide public and private stakeholders with a dynamic opportunity with which to manage investments, capture value movements of assets, prioritize expenditures, and hedge risk.

A health IT platform that provides outcomes-based clinical decision support and applies a financial derivatives model to mitigate risk facilitates evidence-based management for both public and private stakeholders. Data captured by health IT platforms, if shared in a transparent and responsible fashion, could revolutionize both the healthcare and financial markets by improving the quality of care, reducing waste, and contributing to market efficiencies. Achieving these goals requires an ability to access robust data and a mechanism for translating the data into meaningful metrics.

Insofar as recent legislative initiatives, including the Patient Protection and Affordable Care Act (PPACA) and the Health Information Technology for Economic and Clinical Health (HITECH) Act, ${ }^{5}$ increase the demand for health IT and outcomes-based metrics, this discussion is both timely and prudent. For example, new regulations governing medical loss ratios place a cap on non-medical expenditures, but exclude from the calculation any activity that improves health care quality. ${ }^{6}$ Accountable care organizations $(\mathrm{ACOs})$ are designed to use evidence-based approaches to improving the quality of care, ${ }^{7}$ while meaningful use requirements are structured to reward providers who use health IT to improve the process of care

$5 \quad$ Patient Protection and Affordable Care Act, Pub. L. 111-148 (March 23, 2010); American Recovery and Reinvestment Act of 2009, Pub. L. 111-5, Title XIII-IV (Feb. 17, 2009).

6 See U.S. Gov'T ACCOUNTABILITy OfFICE, GAO-11-711, Private HEALTH INSURANCE: EARLY EXPERIENCES IMPLEMENTING NEW MEDICAL Loss RATIO REQUIREMENTS, at 5-6 (2011) [hereinafter 2011 GAO REPORT]. Activities that improve health care quality "include activities designed to increase the likelihood of desired health outcomes in ways that can be objectively measured." $I d$. at 6 .

7 See, e.g., Thomas L. Greaney, Accountable Care Organi-zationsThe Fork in the Road, 364 NEW ENG. J. MED. e1(1) (2011). 
and patient outcomes. ${ }^{8}$ The Office of the National Coordinator for Health Information Technology, ${ }^{9}$ along with the Patient Centered Outcomes Research Institute (PCORI), are charged with using health outcomes research and health IT to improve the quality of health care by promoting and facilitating evidence-based medicine. Insofar as each of these areas stands to benefit from HOIs and HOIbased derivatives, contemplating potential uses informs contemporary discussion of scientific, regulatory, and bioethical concerns.

\section{Health Outcomes Metrics}

Population-level health status metrics have been in existence for no less than five decades. ${ }^{10}$ While a number of current indicators provide valuable information for specific aspects of the health care industry, there is no widely accepted metric that measures the burden of disease over time. ${ }^{11}$ This is problematic, since providers tailor treatment plans and conduct therapeutic interventions based on suspected or confirmed diseases. Similarly, life sciences companies create pharmaceuticals, biologics, and other medical products based on their ability to treat diseases. In addition, public health agencies, patient advocacy groups,

8 See, e.g., David Blumenthal, Launching HITECH, 362 NEW ENG. J. MED. 382, 384 (2010). In addition, through health information exchanges, states and the federal government are creating integrated forums for electronic health records and contemplating use of aggregated and de-identified data for population-based research. See Parasidis, supra note 2, at 966-67.

9 The Office of the National Coordinator for Health Information Technology "is the principal Federal entity charged with coordination of nationwide efforts to implement and use the most advanced health information technology." About $O N C$, U.S. Dept. of Health and Human Services, available at http://healthit.hhs.gov/portal/server.pt/ community/healthit_hhs_gov_onc/1200.

10 See E. Kaltenthaler, R. Maheswaran, \& C. Beverley, Population-based Health Indexes: A Systematic Review, 68 HEALTH POLICY 245, 246 (2004).

11 See Efthimios Parasidis et al., A Dynamic Method for Quantifying Healthcare Status and Burden of Disease Through Health Outcomes Indices, 15 TECHNOLOGY \& INNOVATION 31, 31 (2013). 
and provider networks coordinate management plans with the goal of addressing patients with specific diseases. As such, the preferred method of measuring health outcomes at the population level should match industry's primary concern, which is treating patients by disease in order to improve health outcomes.

The lack of robust outcomes-based metrics hinders detailed evaluation of treatment options and contributes to health inequalities. For example, antibiotic use varies significantly by geography, yet current metrics do not permit clinical evaluation of whether such use correlates with improved health. ${ }^{12}$ Similarly, although chronic disease management is known to vary drastically by zip code, ${ }^{13}$ a dearth of outcomes data precludes meaningful comparative effectiveness research and hinders the ability of public health specialists to address health disparities across socioeconomic dimensions. ${ }^{14}$ Even within a single-payer framework, such as Medicare or the U.S. Department of Veterans Affairs (VA), there is significant regional variation in cost, quality, and quantity of health care. ${ }^{15}$

12 See M. Steinman, Variation in Outpatient Antibiotic Prescribing in the United States, 15 AM. J. MANAG. CARE 861 (2009); Antibiotics Aren't Always the Answer, U.S. CENTERS FOR DISEASE CONTROL AND PREVENTION, available at http://www.cdc.gov/Features/getsmart (last accessed Aug. 21, 2012); see also Michael E. Porter \& Elizabeth Olmsted Teisberg, Redefining Competition in Health Care, HARVARD BUSINESS REV., at 1 (June 2004), available at http://hbr.org/web/extras/insightcenter/health-care/redefining-competition-in-health-care (arguing that, across the health care industry, "[t]here are wide and inexplicable differences in costs and quality among providers and across geographic areas").

13 See, e.g., Diabetes Report Card, CENTERS FOR DISEASE CONTROL, at 3 (2012) [hereinafter 2012 CDC Diabetes Report Card], available at http://www.cdc.gov/diabetes/pubs/pdf/DiabetesReportCard.pdf.

14 See, e.g., Parasidis et al., supra note 11, at 31.

15 Leonard E. Egede et al., Regional, Geographic, and Ethnic Differences in Medication Adherence Among Adults with Type 2 Diabetes, 45 AnNals Pharmacotherapy 169, 170 (2011); Porter \& Teisberg, supra note 12, at 5 (noting that "there is an almost threefold variation in annual costs per Medicare enrollee [and] higher costs are not associated with better medical outcomes and cannot be explained by differences in age, sex, race, rates of illness (which affect the need for care) or cost of living (which affects the cost of delivering care)"). 
Improved health outcomes are important to promote occupational, social, and family productivity, and to enhance treatment effects, all of which can reduce the cost of health care. However, due to the rising costs of health care and the lack of an objective and quantitative method to value health outcomes, there exists a substantial risk for payer-based decisions to cut products and services without knowing what the effects of the cuts will be on the health of patients. HOIs endeavor to fill this void by providing stakeholders with a dynamic and accurate metric that measures and assesses patient outcomes over time.

The guiding principles underlying the HOI model are to (1) determine if populations are better off today than they were in the past, (2) facilitate comparative effectiveness research, and (3) assist in identifying and addressing health disparities by demography and geography. ${ }^{16}$ Whereas the method of creating HOIs has been discussed in the literature, ${ }^{17}$ this Essay highlights the three-phased process and uses diabetes as an example of how HOIs may be applied to clinical care and disease management.

The three-phased approach to the HOI model proceeds as follows: In HOI Phase I, the target population and the outcome-of-interest must be clearly identified. ${ }^{18}$ HOI Phase II includes data collection and algorithm generation. ${ }^{19}$ For both areas, one must consider relevant clinical, economic, and humanistic data. ${ }^{20}$ Data sources may include electronic medical records, patient registries, adverse event reports,

16 See Parasidis et al., supra note 11, at 33-34.

17 See generally Id.

18 See Id. at 34.

19 See Id. at 34-35.

20 See Id. at 34. Clinical data refers to: "Outcomes related to treatment failures, signs, symptoms, and biomarkers specific to each disease being measured. Clinical outcomes relevant to each disease are typically discussed in the medical literature and can be confirmed by clinician panels and real-world evidence [for each HOI]." Id. Economic data refers to: "Financial-related outcomes such as direct and indirect costs of treating diseases. Economic outcomes can include those measured through cost-benefit, cost-minimization, cost-effectiveness, cost-utility, burden-of-illness, and resource-utilization analyses." Id. Humanistic data refers to: "Quality of life, productivity and other patient-reported outcomes measured largely through surveys." Id. 
clinical trial data, post-market research, patient surveys, quality of life indicators, and peer-reviewed literature. ${ }^{21}$ The second component of Phase II-algorithm generationrefers to the creation of an algorithm that assigns relative weights to the data in order to produce a metric that reflects the outcome of interest. ${ }^{22}$ Throughout the HOI process, consultation with specialists and key opinion leaders is essential to ensure that: (a) the underlying sources provide reliable data that reflect the burden of disease, and (b) the algorithm combines the data in a way that produces an accurate measure of outcomes. ${ }^{23}$ HOI Phase III involves risk adjustment and baselining the population to ensure that statistically significant figures can be produced. ${ }^{24}$

Envisioning the HOI model is best achieved through a case study, and type 2 diabetes provides an illuminating paradigm. Type 2 diabetes affects over 24 million Americans, while an additional 75 million Americans have been diagnosed with prediabetes. ${ }^{25}$ Annual medical costs exceed $\$ 218$ billion, and the Centers for Disease Control and Prevention (CDC) predicts that, if current trends continue, by 2050 one in three adults will have the disease. ${ }^{26}$ Diabetes leads to many health ailments and complications that include heart disease, stroke, vision loss, kidney failure, and amputations. ${ }^{27}$ Effective control of glucose and blood pressure can prevent or delay these complications. ${ }^{28}$

21 See Id. at 35.

22 See Id. at $34-35$.

23 See Id. at $35-37$.

24 See Id. at 35.

252012 CDC Diabetes Report Card, supra note 13, at 1 . Worldwide, diabetes has become one of the leading chronic diseases, with prevalence and incidence rates far higher than predicted. M. Uusitupa, J. Tuomilehto, \& P. Puska, Are We Really Active in the Prevention of Obesity and Type 2 Diabetes at the Community Level?, 21 NUTRITION, METABOLISM \& CARDIOVASCULAR DISEASES 380, 380-81 (2010).

262012 CDC Diabetes Report Card, supra note 13, at 2; Egede et al., supra note 15 , at 169 .

272012 CDC Diabetes Report Card, supra note 13, at 1.

28 Id.; Andrea C. Tricco et al., Effectiveness of Quality Improvement Strategies on the Management of Diabetes: $A$ Systematic Review and Meta-Analysis, 379 LANCET 2252 (June 16, 2012); Egede et al., supra note 15 , at 169 . 
Yet, despite decades of attention, "still today no serious strategy exists to address the need to prevent the rapidly rising population of people with diabetes." 29

Diabetes rates vary significantly across demographic and geographic characteristics. Rates of diabetes among American Indian and Alaskan natives (16.1\%) are more than twice those of non-Hispanic whites $(7.1 \%)$, while rates among Hispanics (11.8\%) and non-Hispanic blacks (12.6\%) are notably higher when compared to non-Hispanic whites (7.1\%). ${ }^{30}$ Across the United States, prevalence rates range from $5.8 \%$ in Vermont to $11.3 \%$ in Mississippi, and the southeastern portion of the United States has a disproportionately high percentage of citizens with diabetes. ${ }^{31}$ Preventative care also varies dramatically by state. For example, $73.2 \%$ of patients in Tennessee measure their blood sugar daily, compared to $55 \%$ in South Dakota. ${ }^{32}$ In New York, $40.9 \%$ of patients have attended a diabetes self-management class, compared to $77.1 \%$ in Minnesota. ${ }^{33}$ Research has also documented statistically significant racial and ethnic differences in medication adherence for diabetes patients within a single-payer system such as the VA. ${ }^{34}$

Although the aforementioned data provide general insights into diabetes prevalence and treatment, ${ }^{35}$ the key

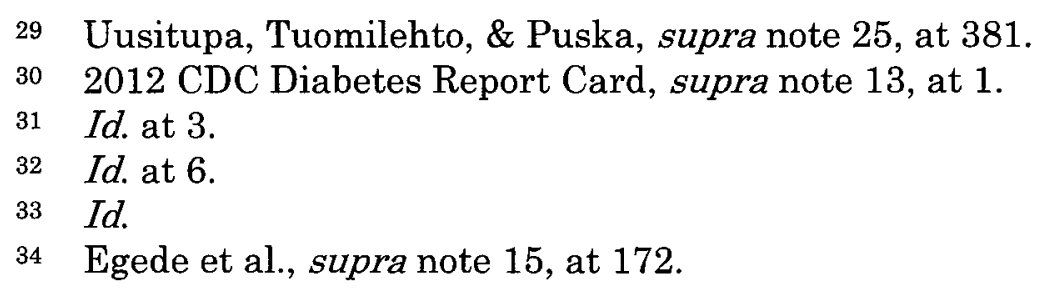

35 Notably, the Patient Protection and Affordable Care Act of 2010 (PPACA) mandates that CDC monitor trends in diabetes and provide the public with current information related to the disease. See 2012 CDC Diabetes Report Card, supra note 13, at inside cover. The annual CDC Diabetes Report Card is the culmination of this work. Despite its mandate, the Report Card almost exclusively focuses on prevalence and disease management compliance rates. The report in passing refers patients to other sources of information, none of which is identified as containing outcomes data. Id. at 7 . While the report provides valuable information, there is no measurement that reflects the extent to which preventative measures lead to improved outcomes. The lack of outcomes data is troubling given the number of patients with diabetes and the cost of care. The CDC report fails to deliver on the agency's promise to provide "public health leadership to translate evidence-based 
questions are whether subpopulations of patients experience better health outcomes and why. Are treatment regimens different? Does one population enjoy better access to healthy and affordable foods? ${ }^{36}$ Is insurance coverage of health club membership relevant? The list could go on, but the point remains - traditional metrics that focus on prevalence and incidence are limited in their ability to assess outcomes.

To be sure, additional studies provide important clinical analysis of patient outcomes. One recent study found that untreated comorbid depression has serious adverse health implications for patients with diabetes, since depression contributes to poor self-care and less treatment, and that there are significant racial and ethnic differences in mental health diagnosis and treatment. ${ }^{37}$ Another found that a small reduction in weight (5\%) translates to a $60-70 \%$ reduction in diabetes risk. ${ }^{38}$ Without question, diabetesrelated research has generated a massive number of peerreviewed articles. For example, a recent search of peerreviewed medical literature retrieved over 160,000 articles related to diabetes over the last decade. ${ }^{39}$

Each study reveals an important piece of the diabetes puzzle. We know that the rates of diabetes are increasing, that there is significant variation in disease treatment and management across sub-populations, and that active disease management can help prevent or delay diseaserelated complications. ${ }^{40}$ We do not know with sufficient certainty whether certain interventions or therapies tend to produce better results, or the extent to which

science on what works into practice to improve health outcomes for people with diabetes." Id. at 8 .

36 See, e.g., Nathan Seppa, Neighborhood Linked to Obesity, SCIENCE NEWS, at 17 (June 2, 2012) (discussing research that found correlations between obesity rates in children and proximity to parks and grocery stores that sell fresh fruits and vegetables).

37 Dara H. Sorkin et al., Underdiagnosed and Undertreated Depression Among Racially/Ethnically Diverse Patients with Type 2 Diabetes, 34 DiABETEs CARE 598, 598-99 (2011).

38 Uusitupa, Tuomilehto, \& Puska, supra note 25, at 387.

39 I conducted the search via PubMed on July 19, 2012.

40 Tricco et al., supra note 28 , at 2252. 
subpopulations need varied approaches to care and management. As a recent meta-analysis of quality improvement strategies and diabetes disease management plans explains, "[a]lthough clinicians, managers, and policy makers expend significant time and resources attempting to optimize care for patients with diabetes, the optimum approach to improving diabetes care (and outcomes) remains uncertain." 41 The HOI model aims to fill this gap.

One of the defining aspects of the HOI model is an algorithm that captures a diverse set of data points. In turn, by creating multiple HOIs for subpopulations, drilldown biomedical informatics capabilities facilitate meaningful comparisons between various groups. Subpopulations can, for example, be stratified by age, gender, ethnicity, insurance coverage, zip code, or other characteristics. Taken together, the HOI model brings together the world of data in a format that provides macro and micro investigation. Figure 1 provides a visual depiction. ${ }^{42}$

FIGURE 1

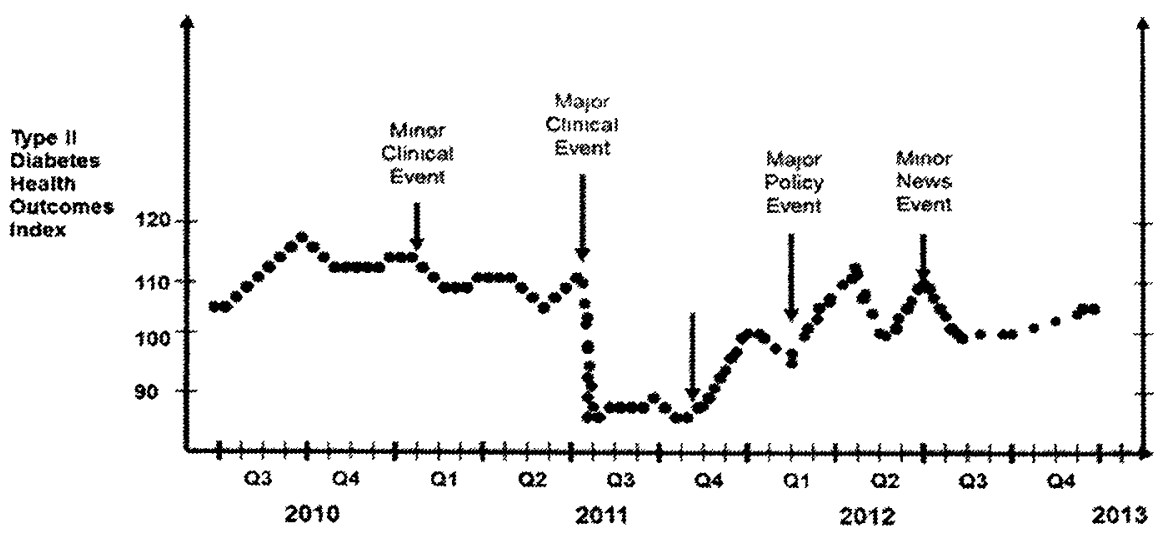

Figure 1 reflects the change in a type II diabetes index over time. As the index increases or decreases, the health of the underlying population can be said to be improving or

$41 \quad I d$.

42 The Figures in this Essay are hypothetical and for discussion purposes only. 
not; robust data mining then allows for a detailed understanding of why. For example, some changes in the index may be correlated with clinical, research and development, or policy events. Further investigation can uncover whether the correlation is statistically significant and whether the underlying changes can inform best practices. As Figure 2 depicts, modeling HOIs across subpopulations of a disease allows for further analysis.

FIGURE 2

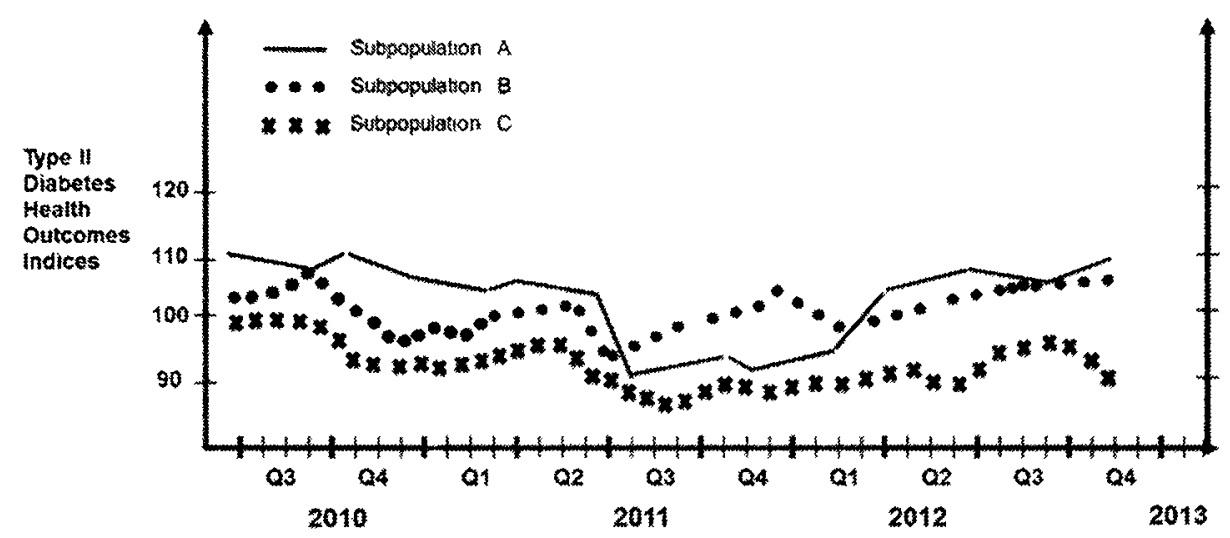

Figure 2 represents an overlay of HOIs for three subpopulations of patients diagnosed with type 2 diabetes. Modeling across subpopulations allows for macro analysis of outcomes at the population level. Examining divergence and convergence, along with trends and comparative rates of increase or decrease, informs disparities-related analysis, and provides an evidence-based approach to clinical care and public health policy. For example, while subpopulations A and B experienced improved outcomes through Q3 and Q4 of 2012, subpopulation C did not. Likewise, the rate of increase across all subpopulations varies for much of the examined time period. Unraveling the components of each HOI can help reveal why.

Figure 3 provides an example of how one may parse out the components of multiple indices to understand how each component is changing over time. As Figure 3 illustrates, each factor (Economic, Clinical, and Humanistic) may be comprised of multiple components. Similarly, each 
component can be broken down into sub-components to permit a more detailed analysis. ${ }^{43}$ By way of example, Figure 3 represents data from the three subpopulations of Figure 2, where each factor is comprised of three components.

\section{FIGURE 3}

\begin{tabular}{|c|c|c|c|c|c|c|}
\hline \multicolumn{7}{|c|}{ Type 2 Diabetes Health Outcomes Indices } \\
\hline & \multicolumn{2}{|c|}{ SUBPOPULATION A } & \multicolumn{2}{|c|}{ SUBPOPULATION B } & \multicolumn{2}{|c|}{ SUBPOPULATION C } \\
\hline & INDEX & \% CHANGE & INDEX & $\%$ CHANGE & INDEX & $\%$ CHANGE \\
\hline \multicolumn{7}{|l|}{ ECONOMIC } \\
\hline E1 & 133.2 & $+2.3 \%$ & 128.9 & $-0.8 \%$ & 150.7 & $-1.4 \%$ \\
\hline E2 & 87.9 & $+1.1 \%$ & 90.9 & $+0.3 \%$ & 92.2 & $+1.5 \%$ \\
\hline E3 & 112.5 & $-3.0 \%$ & 115.7 & $+0.5 \%$ & 119.6 & $-2.5 \%$ \\
\hline \multicolumn{7}{|l|}{ Clinical } \\
\hline $\mathrm{Cl}$ & 89.7 & $+1.1 \%$ & 90.8 & $+1.9 \%$ & 92.7 & $+2.7 \%$ \\
\hline $\mathrm{C} 2$ & 95.8 & $-0.4 \%$ & 99.6 & $-1.2 \%$ & 90.9 & $-1.2 \%$ \\
\hline $\mathrm{C} 3$ & 121.1 & $+2.3 \%$ & 112.8 & $-0.9 \%$ & 124.8 & $+0.2 \%$ \\
\hline \multicolumn{7}{|l|}{ HUMANISTIC } \\
\hline $\mathrm{H} 1$ & 104.6 & $+3.4 \%$ & 100.9 & $+0.1 \%$ & 90.8 & $-1.1 \%$ \\
\hline $\mathrm{H} 2$ & 100.3 & $+0.9 \%$ & 104.6 & $+0.4 \%$ & 88.3 & $-0.4 \%$ \\
\hline $\mathrm{H} 3$ & 88.7 & $+1.3 \%$ & 92.6 & $-1.1 \%$ & 82.4 & $-2.1 \%$ \\
\hline $\mathrm{HOI}$ & 109.8 & $+1.4 \%$ & 106.4 & $+0.7 \%$ & 92.3 & $-2.8 \%$ \\
\hline
\end{tabular}

As Figure 3 illustrates, comparative analysis of the economic, clinical, and humanistic factors across subpopulations reveals detailed information on what drives variation in health outcomes. For example, the outcomes of subpopulation A increased at a rate twice that of subpopulation B. Examining the components of each data set reveals the key drivers behind this disparity. Between subpopulations $\mathrm{A}$ and $\mathrm{B}$, components E1, C3, HI, and H3 were notably higher for subpopulation $\mathrm{A}$, both in terms of raw score and percent change over time. As a whole, while outcomes for subpopulation A improved more than subpopulations B and C, aspects of the B group (such as E3 and $\mathrm{C} 1$ ) improved at a rate higher than the $\mathrm{A}$ group, and aspects of the $\mathrm{C}$ group (E2 and $\mathrm{C} 1$ ) improved at a rate greater than both the $\mathrm{A}$ and $\mathrm{B}$ groups. This was true

43 For the sake of brevity, the subcomponents are not identified in Figure 3. Subcomponents of E1, for example, would include E1a, E1b, . . . E1x. 
despite significantly lower outcomes for the $\mathrm{C}$ group. Targeting specific components through disease management plans may increase the likelihood that outcomes will improve for each subpopulation.

In essence, each HOI is created by meaningfully combining relevant data, and may be dissected to reveal the extent to which individual factors impact health outcomes. Many sectors have utilized indices as a helpful method of measuring and assessing economic and social trends, ${ }^{44}$ and one provider network in Minnesota recently created a composite measure for diabetes care for individual patients. ${ }^{45}$ A dynamic population-based health outcomes index can reflect the big picture of the state of disease and can be broken down to determine how subpopulations are dealing with disease. Insofar as the "costly consumption of health services at the macro level originates at the micro level ... [i]f informed decision making shifts the dynamics of these choices, the effects on health care costs and other resources can be sweeping, with ripple effects that influence benefits packages, health insurance premiums, and access to care." 46 The HOI model represents a promising tool that can help achieve these goals.

\section{Health OUtcomes-Based Financial DeRivative INSTRUMENTS}

In addition to serving as a tool with which to measure and assess health outcomes, HOIs may provide a basis from which to create financial derivative instruments. 47

44 The housing industry, with the Case-Shiller Home Price Indices, is a notable example. See generally S\&P DOW JONES INDICES, S\&P/Case-Shiller Home Price Indices Methodology (Nov. 2009).

45 See Young, supra note 1 , at 580 (indicating that the measure includes "a patient's results for hemoglobin, A1c, blood pressure, and cholesterol").

46 See Woolf et al., supra note 3, at 298.

47 While health care as whole is not a commodity, there are aspects of the health care industry that may be properly characterized as a commodity. See Porter \& Teisberg, supra note 12, at 4; Edmund D. Pellegrino, The Commodification of Medical and Health Care: The Moral Consequences of a Paradigm Shift from a Professional to a 
Derivatives offer stakeholders a unique means of managing risk and investments. ${ }^{48}$ By using derivatives to hedge risk, companies aim to reduce variability and volatility in financial performance and cash flows, two goals that are highly valued in the business and investment communities. ${ }^{49}$ The allure of derivatives is best illustrated by the value of existing contracts. In December 2011, the notional value of over-the-counter derivatives was estimated at over $\$ 640$ trillion, ${ }^{50}$ an amount that dwarfs the $\$ 69$ trillion of total global GDP.51 Although the recent financial crisis has highlighted problems with the derivatives market, 52 derivatives are not inherently corrupt and, if properly used and regulated, could provide significant benefits to stakeholders throughout the healthcare industry. ${ }^{53}$ For purposes of this Essay, I discuss

Market Ethic, 24 J. MED. \& PHILOsophy 243, 247 (1999) (arguing that "[c]ommodities may be used in the process of providing care, but the totality of health care itself is not a commodity").

48 See James A. Hayes, Joseph B. Cole, \& David I. Meiselman, Health Insurance Derivatives: The Newest Application of Modern Financial Risk Management, 28 Business EConomics 1 (April 1993). Derivatives include swaps, options, swaptions (options to enter into swaps), futures, and forward contracts. See Derivative Instruments and Hedging Activities, ERnST \& Young REPORT, at 12 (Sept. 2011) [hereinafter ERNST \& YOUNG REPORT]. By shifting risk to those who prefer to carry risk or are paid to do so, derivatives facilitate focused investments and wealth maximization. See Hayes, Cole, \& Meiselman, supra, at 1 .

49 See ERNST \& Young REPORT, supra note 48, at A-1 (in-dicating that analysts and investors reward companies who do not have volatility in earnings).

50 See Global OTC Derivatives, The EConomist (May 12, 2012), available at $\mathrm{http}: / / \mathrm{www}$.economist.com/node/21554558. This represents an increase of over 500\% from 2002. See Derivatives, THE NEW YORK TiMES, updated Oct. 19, 2011 (citing figures from the Bank for International Settlements in Switzerland), available at http://topics.nytimes.com/topics/reference/timestopics/subjects/d/derivati ves/index.ctx?partner=rssnyt.

51 See World Bank Data, available at http://www.worldbank.org.

52 See generally L. Randall Wray, The Rise and Fall of Money Manager Capitalism: A Minskian Approach, 33 CAMBRIDGE J. ECON. 807, 809 (2009).

53 See G. Philip Rutledge \& Rob Bertram, A Brief Guide to Financial Derivatives, Pennsylvania Securities Commission $(2 \mathrm{~d}$ ed. 
how HOI-based derivatives may benefit payers, providers, innovators, public health agencies, and patients.

Unexpected volatility could have a devastating impact on payers and other stakeholders. Payers set premiums at a level that aims to cover the cost of care and administrative costs, and to generate profit. New regulations governing medical loss ratios cap the non-medical expenditures for most health plans between $15-20 \%$ of premiums. ${ }^{54}$ Payers are required to refund any portion of premiums that exceed this threshold. ${ }^{55}$ If actual payments exceed anticipated payments, payers are unable to go back and charge additional premiums, and are unlikely to be able to recoup lost expected earnings in subsequent years. ${ }^{56}$

Given the new regulations, now more than ever, how payers determine coverage and reimbursement rates is of integral importance. Absent robust outcomes-based metrics, patients and providers run the risk that payers will limit coverage or reimbursement primarily for business reasons, or in a way that negatively impacts the quality of care. While HOIs can serve as tools that use outcomesrelated data to help set coverage and reimbursement rates,

1995), available at http://www.psc.state.pa.us/corpfinance/derivatives. html. The use of derivatives dates back at least to the nineteenth century, when farmers and traders bought and sold corn futures in an effort to reduce risk. See, e.g., Derivatives, supra note 50 . Since that time, "a bewildering variety of derivatives have been developed." Id. Stakeholders in the health care industry have a history of using derivatives to hedge risk. For example, non-profit health care providers have successfully used derivatives to manage long-term debt acquired to finance information infrastructure and clinical equipment needs. See, e.g., Louis J. Stewart \& Vincent Owhoso, Derivative Financial Instruments and Nonprofit Health Care Providers, 31 J. HEALTH CARE FINANCE 38, 38 (2004). In addition, health insurance futures contracts have been discussed in the literature since at least the 1990s. See, e.g., Hayes, Cole, \& Meiselman, supra note 48 , at 1.

5445 CFR 158, 76 Fed. Reg. 76574 (Dec. 7, 2011).

55 Id.

56 Implementation of health insurance exchanges under PPACA is likely to lead to increased competition in the insurance market, and thus insurance companies must be mindful of increases in premiums. Given increased competition and the need to offer competitive rates, insurance companies may find it difficult to increase premiums to the point where lost expected earnings can be recovered. 
HOI-based derivatives can serve as a means of hedging risk in this area. ${ }^{57}$

As a buyer, payers are likely to take a long position to hedge risk that payments in a given year will exceed estimates for certain subpopulations of their covered lives, for example, patients with chronic or costly diseases. As sellers, providers or innovators are likely to take a short position, insofar as lower-than-expected claims implies less services rendered and medical products used. 58 As studies have revealed, with increasing co-payments and higher deductibles, patients are often electing to forego nonessential treatment. 59 Moreover, as patients gain access to outcomes data that reveals increased risk of complications, they are refusing or deferring treatment. 60 This creates risk for providers and innovators that hedging could mitigate.

Innovators face further uncertainties. The costs of drug development are massive - current estimates place the figure at $\$ 1.2$ billion - while the risks are high. ${ }^{61}$ For drugs that enter human clinical trials, approximately $8 \%$ earn FDA approval. ${ }^{62}$ Taken together, high development costs and low approval rates hinder innovation. Studies have documented the lack of innovative medical products and industry's focus on me-too drugs, which are drugs that mimic successfully marketed products. ${ }^{63}$ HOI-based

57 See Stephen P. D’Arcy \& Virginia Grace France, Catastrophe Futures: A Better Hedge for Insurers, 59 J. RISK \& INSURANCE 575, 580 (1992).

58 See, e.g., Hayes, Cole, \& Meiselman, supra note 48, at 1 (indicating that payers and providers are natural buyers and sellers of futures contracts related to insurance coverage).

59 See Anne B. Martin et al., Growth in US Health Spending Remained Slow in 2010; Health Share of Gross Domestic Product Was Unchanged from 2009, 31 HEALTH AFFAIRS 208 (Jan. 2012); Woolf et al., supra note 3 , at 294.

60 See Martin et al., supra note 59, at 208; Woolf et al., supra note 3 , at 294.

61 See Christopher Paul Adams \& Van Vu Brantner, Spending on New Drug Development, 19 HEaLTH ECON. 130, 138 (2010).

62 See Editorial, Mechanism Matters, 16 NATURE MEdicine 347 (2010).

63 See, e.g., Brita Pekarsky, Should Financial Incentives be $U_{\text {sed }}$ to Differentially Reward 'Me-Too' and Innovative Drugs?, 28 
derivatives can spur innovation by allowing innovators to hedge risk. ${ }^{64}$ For example, innovators can buy a long position that their product will fail, while competitors could purchase short positions that would mitigate the risk of a successful new product capturing market share.

Use of HOI-based prediction markets is also worth exploring. A myriad of factors impacts the ability of stakeholders to forecast accurately the demand for medical services and products. ${ }^{65}$ Prediction markets aim to improve the decision-making process by providing a forum for trading contracts that yield payments based on the outcome of uncertain events.66 Prediction markets have the potential to help businesses manage investments, and help governments make better policy decisions. ${ }^{67}$ In the health care arena, prediction markets have been used to predict the likelihood of a nationwide flu epidemic and the success

PhARMACOECONOMICS 1, 2 (2010); I. Kola, The State of Innovation in Drug Development, 83 Clinical PhaRmacology \& THERAPEUTICS 227 (2008).

64 See D'Arcy \& France, supra note 57, at 579 (arguing that, if used properly, futures contracts can lower entry costs for a company).

65 See U.S. AGENCY FOR INTERNATIONAL DEVELOPMENT, QUANTIFICATION OF HEALTH COMMODITIES: A GUIDE TO FoRECASTING AND SUPPLY PLANNING FOR PROCUREMENT, at 8-16 (March 2009) [hereinafter USAID REPORT]. These include changes in policies, the emergence of new products, changes in financing, changes in coverage and reimbursement rates, newly discovered risk-benefit information, geographic variation in incidence and severity of disease, and changes in the political, legal, or regulatory environment. See Id. at 8.

66 Kenneth J. Arrow et al., The Promise of Prediction Markets, 320 SCIENCE 877, 877 (May 16, 2008); see generally MiCHAEL ABRAMOWICZ, PRedictocracy: Market Mechanisms For Public and PRIVATE DECISION MAKING (Yale University Press 2008) (discussing prediction markets); Justin Wolfers \& Eric Zitzewitz, Prediction Markets, 18 J. ECON. PeRsPectrves 107 (2004) (same). The utility of prediction markets lies in their ability to forecast. See Philip M. Polgreen, Forrest D. Nelson, \& George R. Neumann, Use of Prediction Markets to Forecast Infectious Disease Activity, 44 HEALTHCARE EPIDEMIOLOGY 272 (Jan. 2007), available at http://cid.oxfordjournals.org/content/ 44/2/272.full.pdf + html. The trading price of the financial instrument reflects "a consensus belief about the future value of the instrument and thus can be used as a prediction of the future event." Id.

67 See Arrow et al., supra note 66, at 877. 
of new drug treatments. ${ }^{68}$ For example, Eli Lilly and Company has used internal prediction markets to help predict which drugs under development have the best chance of advancing through clinical trials. ${ }^{69}$

Preliminary research reveals that when prediction markets use clinical data and expert opinions, they can be useful in tracking and forecasting infectious diseases, can "inform treatment, prevention, and policy decisions... [and] help to refine existing surveillance systems."70 For example, prediction markets may help estimate the success of interventions or predict the likelihood that a new drug or vaccine earns regulatory approval. ${ }^{71}$ Prediction markets can also be used to predict the timing and strain of seasonal influenza, which could help public health officials and manufacturers of vaccines. ${ }^{72}$ While prediction markets have limitations and their applicability in the healthcare arena needs further validation, preliminary findings suggest that the markets could supplement the existing business and policy framework. ${ }^{73}$

It is again worthwhile to note that the goal of this Essay is to contemplate the next quarter century of health care law. Indeed, there are important details that would need to be addressed for outcomes-based derivatives to be implemented. ${ }^{74}$ These include transparency in the creation of the underlying metric and market confidence in the metric's ability to accurately reflect risk-adjusted health outcomes. Other factors include accounting and tax issues, the legal and regulatory framework, the role of

68 See Id. The Iowa Electronic Health Markets are paradigmatic. See Iowa Electronic Health Markets, available at http://iehm.uiowa.edu/ iehm/index.html (last visited Aug. 30, 2012).

69 See Polgreen, Nelson, \& Neumann, supra note 66, at 273.

$70 \quad$ Id. at 272.

$71 \quad I d$.

72 See Id. at 279.

73 See Id.

74 See, e.g., Hayes, Cole, \& Meiselman, supra note 48, at 1 (identifying factors that are integral to the success of a futures market); Roger W. Gray, Why Does Futures Trading Succeed or Fail: An Analysis of Selected Commodities, in ProceEdings of THE Futures Trading SEMINAR, at 115-37 (1966). 
clearinghouses, and the socio-medical impact of such a market on the industry. ${ }^{75}$ Speculation must also be addressed; while speculators can benefit a futures market through an influx of liquidity, the risk of price destabilization is real. ${ }^{76}$

Regulation should aim to limit the impact of speculation on derivatives markets, and particularly for health-based derivatives where contract prices are likely to impact noncontracting parties such as patients. As a former CFTC commissioner succinctly stated, "[w]e need a sheriff in the saddle, to make sure these markets are honest." 77 Insofar as forecasting supply and demand in the health care industry is challenging and the stakes are high, ${ }^{78}$ effective use of HOI-based derivatives will provide health care stakeholders with an additional tool with which "to more accurately predict financial performance and manage the investment community's expectations.”79

\section{CONCLUSION}

At a time where informatics capabilities and interest in outcomes-related data are flourishing, the demand for meaningful outcomes metrics is likely to produce a myriad of products and services. ${ }^{80}$ This shift may help address one

75 See e.g., Wray, supra note 52, at 809 (discussing derivatives and Warren Buffett's term "financial weapons of mass destruction" as it relates to the derivatives market); Neil Duxbury, Do Markets Degrade?, 59 MODERN L. REV. 331 (1996).

76 See, e.g., Megan S. Chapman, Rising Global Food Prices: The Need for Re-regulating Commodity Futures, 9 SUSTAINABLE DEVELOPMENT LAW \& POLICY 43, 43 (2008), available at http://digitalcommons.wcl.american.edw/cgi/viewcontent.cgi?article $=108$ $9 \&$ context $=$ sdlp.

77 See Id.

78 See generally USAID REPORT, supra note 65 (outlining the complex process of forecasting and the importance of robust measures in developing an accurate forecast).

79 See ERNST \& Young REPORT, supra note 48, at A-1.

80 See Woolf et al., supra note 3, at 298 ("Perhaps nothing is changing more dramatically in health care than the increased volume and influence of information. Patients face a growing need for assistance in knowledge management and for access to professionals 
of the key ailments of the health care system. Some health economists and health policy experts have argued that the "wrong kinds of competition have made a mess of the American health care system. The right kinds of competition can straighten it out." 81 To the extent that competition in health care has evolved to become zero sum, an alternative approach is preferable. ${ }^{82}$ As Michael Porter and Elizabeth Teisberg explain, remedying the imbalances requires competition:

[I]n the prevention, diagnosis, and treatment of individual health conditions or co-occurring conditions. It is at this level that true value is created - or destroyed - disease by disease and patient by patient. It is here where huge differences in cost and quality persist. And it is here where competition would drive improvements in efficiency and effectiveness, reduce errors, and spark innovation. ${ }^{83}$

Insofar as "competition at the level of individual health conditions is all but absent," 84 the HOI model aims to fill this gap.

who are qualified for this task. As the volume of information and the complexity of choices increase, this need will only grow more urgent."); Young, supra note 1 , at 578 (noting that public reporting of health outcomes aims to promote transparency and provide patients with relevant information).

81 See Porter \& Teisberg, supra note 12 , at 1.

82 See $I d$. at 2 . In particular, rather than focusing on cost reduction the market focuses on cost shifting. Id. (explaining that "[c]osts are shifted from the payer to the patient, from the health plan to the hospital, from the hospital to the physician, from the insured to the uninsured, and so on"). This process creates no net value, and typically adds significant administrative costs. See Id. Moreover, many health plans incentivize cheaper, rather than effective, treatments. See Id. For example, since the commitment between patient and health plan is typically for one year, "both payers and employers are motivated to engage in short-term thinking rather than invest in practices and therapies that will improve value over time." Id. at 4 .

83 See Id. at 2.

84 See Id. at 2-4. As Porter and Teisberg explain, "[c]ompetition at the level of individual diseases and conditions is getting even more 
Accountability in health care depends on accurate, objective, and accessible information related to quality measures and health outcomes. ${ }^{85}$ The stakes are unquestionably high, and a diverse spectrum of stakeholders stands to gain or lose from the influx of information. For example, significant earnings may be at stake if bioinformatics analyses or post-market research reveals that a product is not as safe or effective as believed. Likewise, "the threat of malpractice suits creates risks for providers who try to learn from bad outcomes by measuring and analyzing them." 86 On the other hand, patients and providers can use outcomes-based data to inform medical decisions and clinical care. ${ }^{87}$

Taken together, robust outcomes-based metrics will provide evidence-based clinical decision support and corporate management tools. ${ }^{88}$ As pay-for performance becomes an increasingly important component of the health

important as medical research reveals that diagnoses and treatments should be increasingly specialized." Id. at 4 .

85 See Ezekiel J. Emanuel \& Linda L. Emanuel, What is Accountability in Health Care?, 124 ANN. INTERN. MED. 229, 233 (1996); see generally CASS R. SUNSTEIN, INFOTOPIA: How MANY MINDS PRODUCE KNOWLEDGE (Oxford University Press 2006) (discussing benefits and risks of using information technology to produce evidencebased decisions).

86 See Porter \& Teisberg, supra note 12, at 7 ("Ironically, while technology has made knowledge diffusion faster and easier than ever before, the social and economic structures of the health care sector work against the rapid dissemination of learning.").

87 See, e.g. H. Gilbert Welch, Testing What We Think We Know, NEW YoRK TIMEs (Aug. 19, 2012) (indicating that "for a large part of medical practice, we don't know what works," and calling for more robust outcomes-related research).

88 Given the limited outcomes-related information, patients of-ten are asked to make difficult treatment decisions without meaningful information. See Porter \& Teisberg, supra note 12, at 3; see also Woolf et al., supra note 3 , at 293 (arguing that "[t]he health care system cannot truly support informed decision making without correcting the underlying obstacles that impede patient access to needed information"). Most hospitals and providers do not disclose outcomesdata, often arguing that risk adjustment is impossible or too difficult, or that disclosing outcomes may impact medical malpractice. See Porter \& Teisberg, supra note 12 , at 6 . Yet, outcomes are the ideal method by which to determine treatment options. See Id. at 4. 
care delivery system, accurate outcomes-based metrics are essential to ensuring that performance is evaluated properly. ${ }^{89}$ To ensure that the information is reliable, ${ }^{90}$ regulators and public health specialists must take steps to frame a healthy arena for outcomes-based metrics that incentivize robust disclosure and punish deceptive tactics or the manipulation of data. ${ }^{91}$

89 See, e.g., Id. at 12-13; Young, supra note 1, at 580 (noting that outcomes data is increasingly being incorporated into health system metrics). An example is telling: New York health officials actively collected outcomes data related to cardiac bypass surgeries performed statewide, and made the data publicly available. In response, providers altered treatment methods based on the best outcomes, and some hospitals revoked the privileges of underperforming doctors. Within four years, New York had the lowest risk-adjusted mortality rate in the country. See Porter \& Teisberg, supra note 12, at 6 .

90 See Id. at 7 (noting that "America cannot afford to wait for perfect information to be developed before it can be disseminated. Nothing will drive improvements in information faster than making the existing data widely available.").

91 For public policy decisions in health care to be sound, "they should be based on a solid understanding of the processes that have led to the current situation and some reasoned analysis" of relevant factors. H. Leufkens et al., Scenario Analysis of the Future of Medicines, 309 BRITISH MEDICAL JOURNAL 1137, 1137 (1994). While "[n]ew discoveries constantly advance the possibilities of drug treatment . . . society is increasingly concerned about rising drug costs, safety issues, and the sometimes irrational use of existing medicines." Id. As such, there is a "need for a quantified insight into how drug treatment is actually conducted and what its positive and negative consequences are in terms of health, cost, and value for society as a whole." Id.

Conflict of Interest Disclosure: The methods, systems, and apparatus discussed herein were first disclosed in a U.S. patent application titled Computer Implemented Methods, Systems, and Apparatus for Generating and Utilizing Health Outcomes Indices and Financial Derivative Instruments Based on the Indices (US2010/0004945), of which I am a co-inventor. A related patent application is pending in Singapore (No. 201009500-8), and an application has been filed pursuant to the Patent Cooperation Treaty (PCT/US09/49223). The patent applications are assigned to Global Health Outcomes, Inc., of which I am a co-founder, officer, and board member. 
Contemplating new uses of outcomes-based metrics and financial derivative instruments will assist regulators and policymakers in structuring appropriate regulations. Despite the snail-like pace of health IT adoption and implementation, regulators should be mindful to take a proactive approach to structuring a legal framework that harmonizes the interests of patients, providers, payers, and innovators. With a dynamic framework in place, HOIs and HOI-based derivatives stand to assist the health care industry in achieving the aspirational goals of reducing health care costs and improving health outcomes. 



\section{ARTICLES}


